Document downloaded from:

http://hdl.handle.net/10251/37183

This paper must be cited as:

Lloret Romero, MN. (2012). Model for the centralized acquisition of collections in times of crisis. Bottom Line. 25(4):59-63. doi:10.1108/08880451211292603.

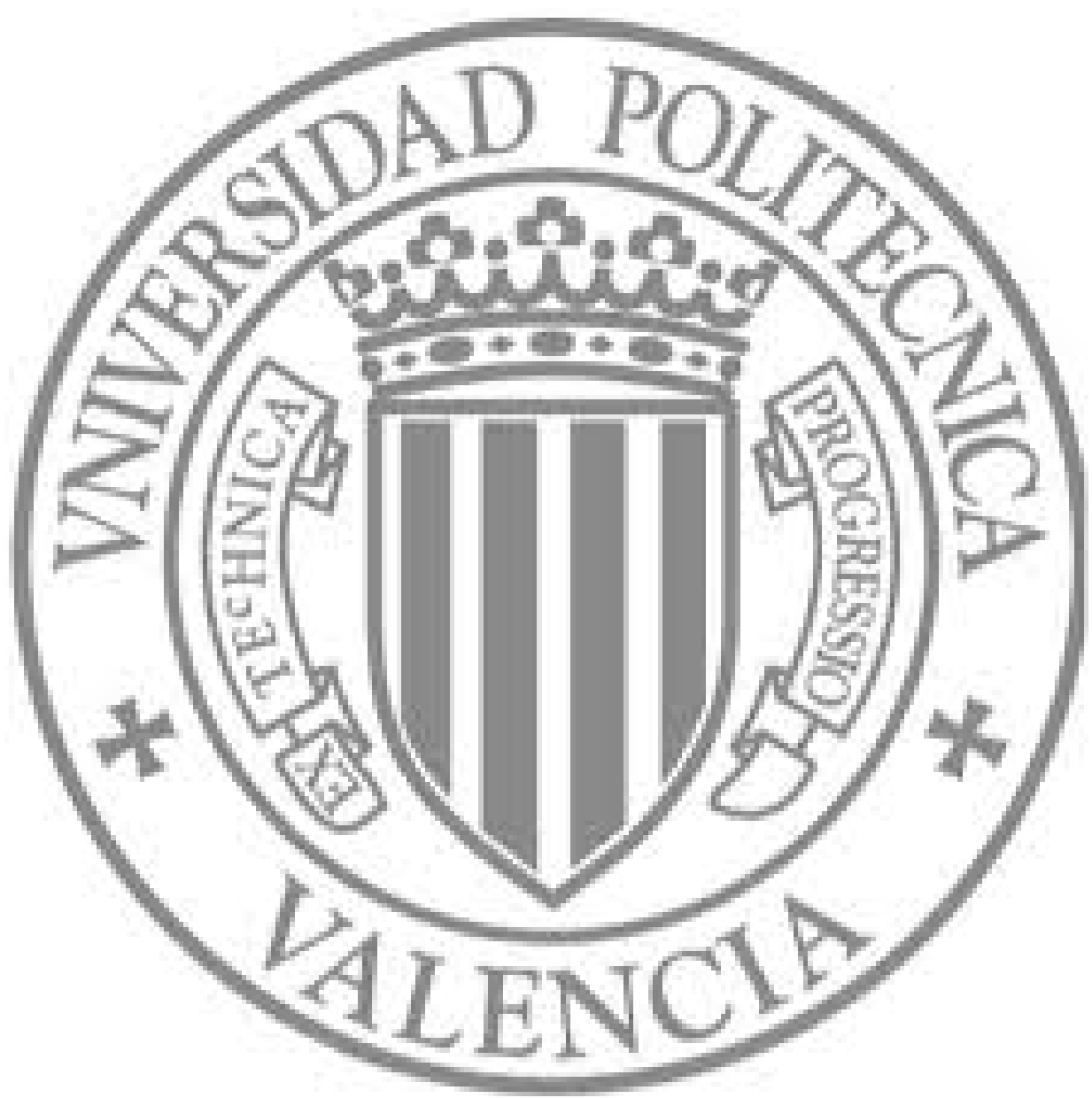

The final publication is available at

http://dx.doi.org/10.1108/08880451211292603

Copyright Emerald 


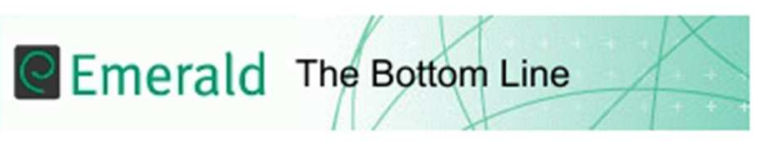

\section{Model for the centralized acquisition of collections in times of crisis}

\begin{tabular}{|r|l|}
\hline Journal: & The Bottom Line: Managing Library Finances \\
\hline Manuscript ID: & Draft \\
\hline Manuscript Type: & Article \\
\hline Keywords: & library consortia, centralized acquisitions \\
\hline
\end{tabular}

SCHOLARONE $^{\text {In }}$

Manuscripts 


\section{Model for the centralized acquisition of collections in times of crisis}

\section{Introduction}

It is common knowledge that in the past 10 years libraries have become, to a greater or lesser extent, electronic resource centers. In many cases, the conversion of analog collections to digital collections is still a paradigm shift with regard to the ownership, use and enjoyment of the collections. However, first and foremost the inclusion of digital collections has led to a new licensing model that has changed the financial management and administration of budgets for the purchase of collections, starting with the acquisition of scientific journals for specialized centers and extending to all types of resource materials.

In the traditional library collection management model, the documents deemed to be most suitable for the libraries were chosen title by title, and the amounts paid were based on the volume of titles chosen. In the analog model, this resulted in a large investment in similar collections in libraries located in close proximity to one another. In research centers and related universities, attempts were made to make coordinated purchases. However, in most cases purchases were made individually, meaning that costs, and specifically direct costs relating to usage, were very high for a usage of journals in the collection which in many cases was very sporadic.

If coordinated purchasing gradually became almost compulsory in the analog world, in the case of electronic collections, the possibility of sharing items digitally accelerated the shift to joint purchasing. In $2001 \mathrm{~K}$. Frazier11 coined the phrase 'Big Deal'.

\section{Library consortia and the Big Deal}

In the Big Deal model editors set a low price for the magazines which have not been subscribed by a group of libraries up to that time, agreeing to group sales and creating price models for pools of buyers based on the use of the collections. This licensing method is highly advantageous to libraries, since on the one hand, they 
only pay for what they use and, on the other hand, this method fosters joint purchasing, which enables users to access a greater number of journals than if purchases had to be made using only each library's small budget. Although this model was originally restricted to journals, its use has currently been extended to all types of formats including books, music and audiovisuals, etc.

In fact, this type of purchase is beneficial for both editors and libraries, especially in the current times of economic crisis, in which the decrease in budgets has made allocating a stable budget to collections almost unfeasible. Libraries can offer a more extensive catalog which enhances their competitive positioning vis-à-vis the user. It also improves the relationship between editors and libraries since having an intermediary to manage subscriptions is no longer as necessary as it was in the case of analog purchases.

The library consortia can be considered heirs of the cooperative movement initiated in the 70s in response to library automation ( 'bibliographic utilities' and 'networks' in the USA, cooperatives in the United Kingdom and cooperative cataloging agencies in Northern European countries). But, as shown by different research articles analyzing their emergence, consortia are a form of cooperation clearly associated with the purchase of electronic information resources. Although there have been times in which consortium purchasing has been looked upon negatively, generally and especially in times of crisis, its need and even increased breadth as compared to previous years is clearly seen. One of the problems arising from the creation of consortia is the legal form of the companies that comprise them. The widespread use of the term "consortium" to refer to entities which jointly license resources, hides the great diversity of legal forms taken by entities performing this type of activities. In each country the consortia are shaped differently. In almost all countries they are generally linked to public or semi-public entities. Although, they originated in universities, consortia are now used in all type of information centers requiring the occasional or general use of collections.

In a few cases, "national licenses" have been used in which so called "joint 
contracts" themselves are not entered into but rather certain licensing conditions are created.

In any case, the aforementioned diversity of legal forms should not obscure the ultimate purpose of these consortia: around the world organizations and structures have been or are being created to allow for joint purchasing so as to benefit from the advantages of the Big Deal.

The library consortia movement has grown to such an extent that in the midnineties the ICOLC (International Coalition of Library Consortia) was created. The ICOLC is an informal association of more than 150 consortia around the world which meet twice a year to exchange information and jointly defend the interests of the libraries comprising them.

Among its advantages, consortium purchasing allows for an equality of conditions with respect to access to information since prices are reduced and contents are shared in a much more extensive way.

As shall be discussed below, over the years the amount of electronic information licensed consortially has greatly increased and has gained popularity, especially since the start of the economic crisis. However one of the impediments preventing this buying format from taking hold is that libraries are often specialised. Many of them require resources that are difficult to share because these materials are for very specific users, and it is quite unlikely for other libraries to be interested in them. In the case of universities, their use has been much more straightforward, since many of the collections have common interest bases. However, in information centers with less generic needs, consortium licensing is much more complicated.

Consortium licensing provides equity to the library system, since without taking into account geographic location and the users' ease of access; they give the same opportunities to users accessing library sources in different ways. In economic terms, joint purchasing reduces costs, freeing funds which can be used for other necessary expenses in the centers. In these times of cuts, this can mean the 
survival of other services, which most certainly have a direct relationship with jobs in these centers. Additionally, the possible extension of the access to resources makes it possible to increase the number of users, which can fully justify an expenditure budget and even an increase in services and collection management needs.

Another advantage of consortium licensing is the need to come to a consensus among institutions regarding purchasing, which implies an ongoing study of the use of the collection in an attempt to streamline purchasing to take into account the resources which are most necessary and most requested. In other words, it promotes the rationalization of spending, since institutions have to account for use leading them to work harder to justify the licensing of resources than in other cases where entities make individual purchases.

-However, there is a clear relationship between cost and improved use in the case of extensions of collections through the consortium. In many cases consortium purchasing does not imply less spending, but rather access to more resources, meaning that more services can be provided with the same budget, which is vital for a fully operating library.

As mentioned earlier, the basic problem with consortium purchasing is that its use is highly centralized in large institutions, although it is actually small centers which are likely to find consortium purchasing most useful. In many cases, small center cannot join such a consortium because their budgets are lower than required. This barrier implies an inequality where the strong still dominate the weak given that those without a high enough budget do not have access to an instrument which does not eliminate spending, but does expand the horizons of its users, thus justifying its use even more. 


\section{Conclusions}

In conclusion, it should be emphasized that the introduction of purchasing consortia in the electronic environment has led to an increase in the collections of all entities, as well as the rationalization of spending on collections, which is more closely related to the needs of the entities' users. However, the use of such consortia should be more extended and rather than being limited to large libraries or institutions, they should be made available to medium-sized groups of entities which can benefit from these instruments. Additionally, if the possibility of accessing resources were to be increased through these consortia, it would be of great interest to include diverse materials such as films and music, etc. that may be of interest to other type of institutions such as those serving the general public.

\section{References}

1. Best, R. D. (2009). "Is the "big deal" dead?" The Serials Librarian 57 (4), 353-363.

2. Jeffrey N. Gatten and Tom Sanville, "An Orderly Retreat from the Big Deal: Is it Possible for Consortia?," D-Lib Magazine 10, no. 10 (October 2004). Available online from http://www.dlib.org/dlib/october04/gatten/10gatten.html

3. Kenneth Frazier. "The Librarian's Dilemma: Contemplating the Costs of the 'Big Deal',' D-Lib Magazine, 7 no. 3 (March 2001). Available online at http://www.dlib.org/dlib/march01/frazier/03frazier.html

4. Oder, N. (2010). "UC libraries, Nature Publishing Group in heated dispute over pricing; Boycott possible." Library Journal. Available online at http://www.libraryjournal.com/l//home/885271264/uc_libraries_nature_publis hing_group.html.csp 
5. Pesch, O. (2008). "Library standards and e-resource management: A survey of current initiatives and standards efforts." Serials Librarian 55 (3), 481-486

6. Peters, Thomas A. (July 2001). "What's the big deal?" Journal of Academic Librarianship, 27 (4):302-304. 